\title{
Livros de artista e livros raros: aproximações
}

Maria do Carmo de Freitas Veneroso

Doutora em Estudos Literários pela Universidade Federal de Minas Gerais. Professora titular da Escola de Belas Artes da Universidade Federal de Minas Gerais.

http://dx.doi.org/10.1590/1981-5344/3240

Neste trabalho são estabelecidos diálogos e cruzamentos entre a Enciclopédia visual, iniciada em 1974 por Wlademir Dias-Pino, a Encyclopédie (1751-1772), de Diderot e d'Alembert, e a Encyclopedia, Contemporary Art in the World, with www.google.com/ language_tools (2010), de Jean-Benoît Lallemand. Enquanto a Enciclopédia visual e a Encyclopédie são obras com características utópicas, que buscam o conhecimento enciclopédico tendendo para um conhecimento universal, a Encyclopedia, Contemporary Art in the World questiona a possibilidade de apreensão do conhecimento total ou universal. A partir da aproximação entre as obras analisadas, nota-se que o enciclopedismo é um tema atual, que perpassa a arte e a cultura, e que em alguns casos são reforçados os princípios do "conhecimento total" da Encyclopédie, enquanto em outros casos essa possibilidade de um saber universal é contestada ou subvertida, pois, apesar da facilidade de acesso à informação na época atual, muitas vezes ela não é absoluta, dependendo do contexto em que é recebida.

Palavras-chave: Livro de artista; Livro raro; Enciclopedismo; Conhecimento universal; Enciclopédia.

\section{Artist's books and rare books: approximations}

This work establishes dialogues and cross-referencing between artists' books, such as the Visual Encyclopaedia, started in 1974 by Wlademir Dias-Pino, the Encyclopédie of Diderot and d'Alembert and the Encyclopedia, 
Contemporary Art in the World, with www.google.com/language_tools (2010), by Jean-Benoît Lallemand. While the Visual Encyclopaedia and the Encyclopedie are works with utopian characteristics, which seek encyclopedic knowledge tending towards universal knowledge, the Encyclopedia, Contemporary Art in the World questions the possibility of apprehending total or universal knowledge. From the approximation of the works analyzed, it can be seen that encyclopedism is a current theme, which runs through art and culture, and in some cases the principles of the "total knowledge" of the Encyclopedie are reinforced and in other cases this possibility of a universal knowledge is contested or subverted, for, despite the ease of access to information in the present time, it is often not absolute, depending on the context in which it is received.

Keywords: Artist's book; Rare book; Encyclopedism; Universal knowledge; Encyclopedia.

Recebido em 31.05.2017 Aceito em 30.06.2017

\section{Apresentação}

Em geral, o estudo de livros de artista e de livros considerados raros se dá separadamente. Porém, no presente artigo, são discutidas algumas aproximações e diálogos entre obras contemporâneas, os livros de artista, e uma obra considerada rara, do século XVIII, pertencentes ao acervo das coleções de Livros de Artista ${ }^{1}$ e de Obras Raras da Divisão de Coleções Especiais da Biblioteca Universitária da UFMG.

Considera-se a possibilidade de estabelecer aproximações entre essas obras que, pela sua própria natureza, pertencem a uma mesma categoria: o livro. O diálogo entre livros de artista contemporâneos e livros considerados raros remete à gênese do livro e da escrita e às relações entre palavras e imagens. A escrita e o livro, nas suas formas mais antigas, como as tabuletas da escrita cuneiforme e os rolos de papiro em escritas hieroglíficas, continham um forte caráter icônico, e a palavra podia ser vista também como imagem, como acontece atualmente em muitos livros de artista.

No caso dos livros de artista abordados, nota-se uma espécie de equivalência entre a imagem e o texto, não havendo, geralmente, uma relação hierárquica entre eles, como ocorre nas ilustrações. Assim, o que há é um diálogo palavra-imagem, em que a palavra pode ser considerada

Sobre a criação da coleção, consultar CADÔR, Amir Brito. Coleção especial: livros de artista na biblioteca. PÓS: Revista do Programa de Pós-Graduação em Artes da EBA/UFMG, Belo Horizonte, v. 2, n. 3, maio 2012. p. 24-32. Disponível em: <http://www.eba.ufmg.br/revistapos/index.php/pos/issue/view/4>. O catálogo da coleção pode ser acessado pelo endereço <https://catalogobiblioteca.ufmg.br/pergamum/biblioteca/index.php>. 
também pelas suas qualidades visuais, podendo ser vista como imagem, ao mesmo tempo que a imagem também pode ser lida como um texto, (considerando o texto do ponto de vista semiológico ${ }^{2}$ ).

Outro fator que aproxima essas obras é o fato de alguns livros de artista eventualmente tornarem-se obras raras, apesar de esse ainda ser um tema controverso. Mais um ponto a ser considerado é que muitas vezes livros de artista subvertem e se apropriam de saberes tradicionais veiculados por livros considerados raros.

Partindo desse pressuposto de que é legítimo aproximar tais livros, focaliza-se o enciclopedismo por autores/artistas que criam enciclopédias como um desejo utópico de abarcar o conhecimento universal e por aqueles que, inversamente, questionam essa possibilidade.

São estabelecidos diálogos e cruzamentos entre as seguintes obras (Figura 1):

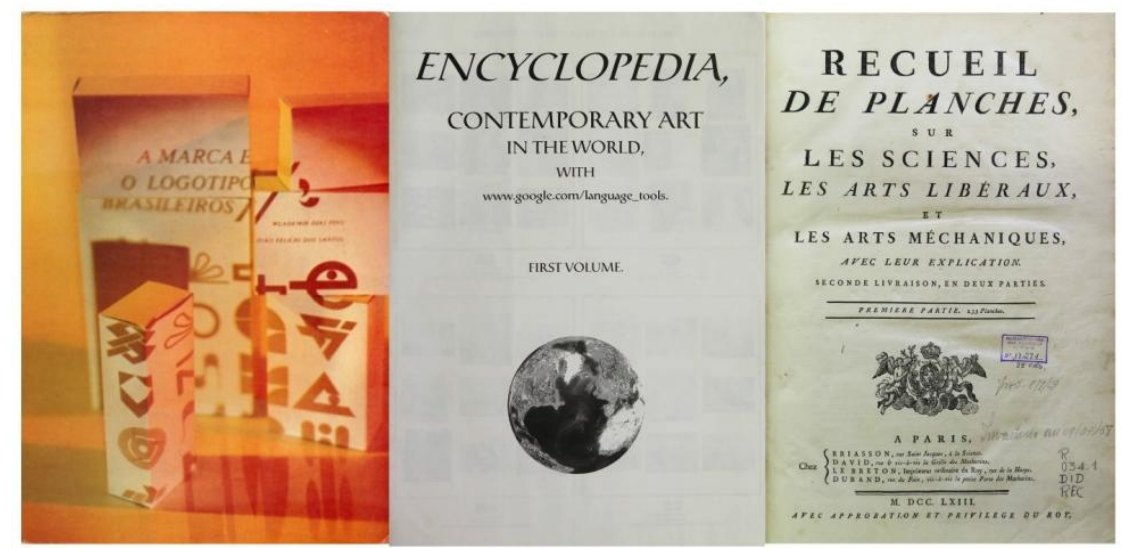

Figura 1 - DIAS-PINO; FELÍCIO DOS SANTOS. Coleção Enciclopédia visual (1974-1991); LALLEMANT. Encyclopedia, Contemporary Art in the World (2010); DIDEROT; D'ALEMBERT. Encyclopedie (1751-1772.

Fonte: acervo da autora.

- Enciclopédia visual, iniciada em 1974 por Wlademir Dias-Pino;

- Encyclopedia, Contemporary Art in the World, with www.google.com/ language_tools (2010), de Jean-Benoît Lallemand;

- Encyclopédie (1751-1772), de Diderot e d'Alembert.

Enquanto a Enciclopédia visual e a Encyclopédie são obras com características utópicas, que buscam o conhecimento enciclopédico tendendo para um conhecimento universal, ao tentarem abarcar a catalogação e a difusão do conhecimento sob a forma de textos e imagens, a Encyclopedia, Contemporary Art in the World questiona a possibilidade de apreensão do conhecimento total ou universal.

${ }^{2}$ A semiologia considera as artes plásticas como um sistema de significação que tem signos tal qual a escrita, fazendo com que a imagem possa ser lida como um texto. 
Para a discussão, em uma abordagem que parte da história cultural e da história da escrita, são privilegiadas as relações interartes, especificamente entre palavras e imagens, abrangendo também atravessamentos transdisciplinares entre as artes e outras disciplinas. No artigo, os seguintes eixos temáticos são explorados: 0 arquivo artístico/literário (a memória no livro) e a letra como imagem, a imagem da letra (as palavras no livro). São estabelecidos diálogos com autores como Peter Burke, Phillip Blom, Anne-Marie Christin e Stéphane Mallarmé/Paulo Pires do Vale.

Esses diálogos transdisciplinares propostos remetem a momentos como o Renascimento, por exemplo, quando figuras como Leonardo da Vinci já produziam obras que muitas vezes privilegiavam o diálogo arteciência, como seus Cadernos (executados no século XV e começo do XVI, sem possibilidade de publicação), considerados precursores do livro de artista contemporâneo. Também pode ser citado como um precursor do livro de artista do século XX Le Corbeau, poema de Edgar Allan Poe, traduzido por Stéphane Mallarmé e ilustrado por Édouard Manet, considerado um dos principais livres de peintre ${ }^{3}$ produzidos no século XIX, entre vários outros, como For the Voice, de El Lissitzky e Maiakovski (1923), e as Palavras em liberdade, de Marinetti.

\section{Em busca de uma definição do livro de artista e do livro raro}

As evidências demonstram que podemos retroceder no tempo quase indefinidamente na busca da origem do livro de artista. Assim, esse é um tema amplo e que pode ser abordado a partir de várias perspectivas. Porém, apesar de haver inúmeros exemplos de livros de artista na história da arte, é somente no final do século $X X$ que 0 entendimento da autonomia desse tipo de obra é legitimado, principalmente a partir dos anos de 1960 , pela mutação causada pela arte conceitual.

Considerando seu sentido lato, "livro de artista" designa um grande campo artístico, no qual o artista se envolve na construção do livro como obra de arte (livro-objeto, livro ilustrado, livro de arte, livro-poema, poema-livro, livro-arte, arte-livro, livro-obra, etc.). O pesquisador Paulo Silveira inclui ainda: "os livros e não-livros escultóricos, certos experimentos digitais, algumas instalações e todo um mundo de objetos ou situações" que ele determina como sendo "livro-referentes', mesmo que remotamente" (SILVEIRA, 2001, p. 25-26), ou seja, os livros de artista no campo ampliado.

Já no seu sentido estrito, "livro de artista" refere-se a um produto específico gerado a partir das experiências conceituais dos anos de 1960. Suas características são: a ênfase na ideia (muitas vezes em detrimento da forma); a transitoriedade e a precariedade dos meios utilizados; a

\footnotetext{
${ }^{3}$ O livre de peintre surge em meados de 1890, como uma iniciativa do marchand Ambroise Vollard, em Paris, e pressupõe a colaboração entre um poeta e um artista na elaboração de um livro, geralmente impresso, utilizando-se processos de gravura e/ou tipografia, em papéis de boa qualidade, em tiragens limitadas e assinadas.
} 
atitude crítica frente às instituições artísticas, as particularidades na forma de circulação e recepção; livros impressos e editados em pequenas e médias tiragens; feitos por artistas e/ou poetas, e que podem envolver textos, imagens ou ambos; neles, texto e imagem geralmente dialogam, sem que exista, necessariamente, uma hierarquia entre ambos: a palavra é imagem, e a imagem pode ser lida como um texto. Seria, nas palavras de Johanna Drucker (2004), o livro de artista como um "múltiplo democrático". Feitas essas considerações, é necessário esclarecer, portanto, que no presente artigo os livros de artista estudados são compreendidos no seu sentido estrito.

Levando em conta a possibilidade de aproximar livros de artista e livros considerados raros, torna-se necessário definir o que se entende por "livro raro". Definir o que torna uma obra "rara" ou "especial" não é uma tarefa simples, já que ainda não existem, no Brasil, critérios absolutos para se determinar a raridade bibliográfica de um livro. A raridade está diretamente ligada à escassez da obra, ou seja, quando a sua procura excede a oferta, tornando-a difícil de ser encontrada devido a uma série de fatores que, isolados ou combinados entre si, determinam a importância dessa obra dentro do universo bibliográfico.

Para compreender o conceito de raridade bibliográfica, foi utilizada a publicação Que é livro raro 1 (1989), da bibliotecária Ana Virgínia Pinheiro (chefe da Divisão de Obras Raras da Biblioteca Nacional), em que é proposta a sistematização dessa metodologia, sugerindo a observação das seguintes características na determinação da raridade de um livro: limite histórico, aspectos bibliológicos, valor cultural da obra, pesquisa bibliográfica, características do exemplar. Ela explica que, a partir desses aspectos, as bibliotecas costumam elaborar critérios para a determinação de raridade, buscando assegurar o tratamento adequado às suas obras. Pinheiro propõe que, "para alcançar o status de raridade, livros devem atender a pelo menos um dos requisitos acima mencionados, sendo que alguns conseguem atender a vários requisitos ao mesmo tempo" (PINHEIRO apud RODRIGUES, 2011, [s.p.]).

É interessante notar que livros de artista têm se tornado, com frequência, livros raros. Assim, o Setor de Obras Especiais da Biblioteca pode ser considerado um lugar adequado para a guarda e a exibição de livros de artista, já que ali eles se encontram em diálogo com livros especiais e raros, como incunábulos e livres de peintres, dos quais eles se aproximam. Apesar de muitos livros de artista serem múltiplos, impressos com a utilização de processos de impressão comercial em papéis de baixo custo, eles costumam tornar-se "raros" ou "especiais" com o passar do tempo. Isso ocorreu, por exemplo, com o livro Twenty-six Gasoline Stations (1962-1963), de Edward Ruscha, uma brochura impressa em offset, em papel de baixa qualidade, com uma tiragem de 400 cópias, cada exemplar sendo vendido por 1 ou 2 dólares. Nessa primeira edição, as cópias eram numeradas, e nas edições subsequentes essa prática foi abandonada. Tratava-se de um "múltiplo democrático", já que o preço e a distribuição permitiam seu acesso a um público relativamente amplo. Com 
o passar do tempo, esse livro tornou-se um ícone, devido a várias razões. Alguns autores o consideram como o primeiro livro de artista realizado, e outros, como Johanna Drucker, apesar de evitarem rótulos como esse, acreditam tratar-se de uma obra importante, pois ela indiscutivelmente inova ao incorporar e definir um livro de artista. Porém, o livro Twenty-six Gasoline Stations, apesar de ter surgido como um "múltiplo democrático" (Johanna Drucker), pode ser considerado atualmente uma obra rara, disputada por colecionadores e vendida por altos valores, se comparados ao preço da época do seu lançamento, já que existem poucos exemplares disponíveis no mercado. Assim, faz sentido que os livros de artista de uma coleção recebam o tratamento dispensado às obras raras/especiais, que é o que eles eventualmente se tornam.

\section{Tudo, no mundo, existe para resultar em um livro, ${ }^{4}$ ou cruzamentos entre a Enciclopédia visual, de Wlademir Dias-Pino, a Encyclopedia, Contemporary Art in the World e a Encyclopédie, de Diderot e D'Alembert}

Empreendimentos enciclopédicos podem ser encontrados desde as tabuletas cuneiformes nos arquivos dos reis da Mesopotâmia, porém não se pode considerar uma enciclopédia "qualquer tipo de obra que aspire a apresentar segundo uma determinada ordem tudo o que se sabe sobre um argumento ou grupo de argumentos [...]" (SALSANO, 2000, p. 380). Não se pode negar que a abordagem enciclopédica desempenhou um importante papel na grande revolução que foi o Renascimento, mas somente no século XVIII se pôde falar de enciclopédia, em seu sentido estrito.

O período moderno, geralmente aceito como os séculos de Gutenberg (século XV) a Diderot (século XVIII), assistiu a uma explosão do conhecimento que se seguiu à invenção da imprensa, aos grandes descobrimentos e à chamada "revolução científica". Grande foi o impacto produzido pela imprensa e pelo desenvolvimento da gravura no Ocidente nesse processo, possibilitando a impressão em massa de textos e imagens.

A impressão gráfica utilizada na difusão do conhecimento através dos livros impressos também contribuiu para a tentativa de abarcar o conhecimento universal, através de obras como a Encyclopédie, que se transformou no maior empreendimento intelectual do século XVIII, na França.

Já a Enciclopédia visual é um projeto grandioso e utópico de catalogação e difusão do conhecimento sob a forma de imagens e palavras, em 1.001 volumes, iniciado por Wlademir Dias-Pino, nos anos 1970. A Enciclopédia visual de Dias-Pino e a Encyclopédie possuem como principal afinidade uma busca utópica por um conhecimento enciclopédico tendendo para um conhecimento universal. Nos dois casos nota-se a

\footnotetext{
${ }^{4}$ Essa afirmação remete à seção emblematicamente intitulada "Quant au livre", que Stéphane Mallarmé dedicou à questão do livro no volume Divagations (1897), onde ele reuniu o essencial de sua obra em prosa.
} 
exploração de diferentes relações entre palavras e imagens. Neste artigo, optou-se por focalizar e comparar a maneira como a Encyclopédie e a Enciclopédia visual abordam a escrita e os alfabetos antigos.

Dias-Pino é um poeta brasileiro que participou da criação do PoemaProcesso, lançado em meados da década de 1960, como uma dissidência do movimento da poesia concreta, no Brasil. Enquanto a poesia concreta possui raízes construtivistas, caracterizando-se pela "exploração da dimensão visual e sonora do poema, vinculando-as à carga semântica das palavras" e utilizando um método de composição baseado na organização rigorosamente geométrica, matemática, racional e objetiva, o PoemaProcesso contrapõe-se a esses ideais de objetividade, explorando a subjetividade e a arbitrariedade dos signos linguísticos. Assim, Dias-Pino preconizava como recurso poético o uso de recodificações alfabéticas (GARCIA, 2012, p. 127-128). (Dias-Pino é considerado, ainda, o autor do primeiro livro de artista brasileiro, $A$ ave, publicado em 1957, época em que a categoria livro de artista ainda não havia sido estabelecida.)

$O$ interesse por novas grafias levou Dias-Pino a identificar a linguagem gráfica das logomarcas como a língua ideal (GARCIA, 2012, p. 129), dando origem ao primeiro volume da Enciclopédia visual, intitulado A marca e o logotipo brasileiros, publicado em 1974, em parceria com João Felício dos Santos. As logomarcas são colocadas, por Dias-Pino, em um vasto contexto de referências, como reproduções de obras de arte, escrituras, fotografias, desenhos, poemas visuais, pictogramas.

$\mathrm{Na}$ década de 1990 foram publicados mais seis volumes da Enciclopédia visual, entre eles Escritas arcaicas (Figura 2), que faz referência a escritas antigas de diversas partes do mundo, que deram origem a vários alfabetos.

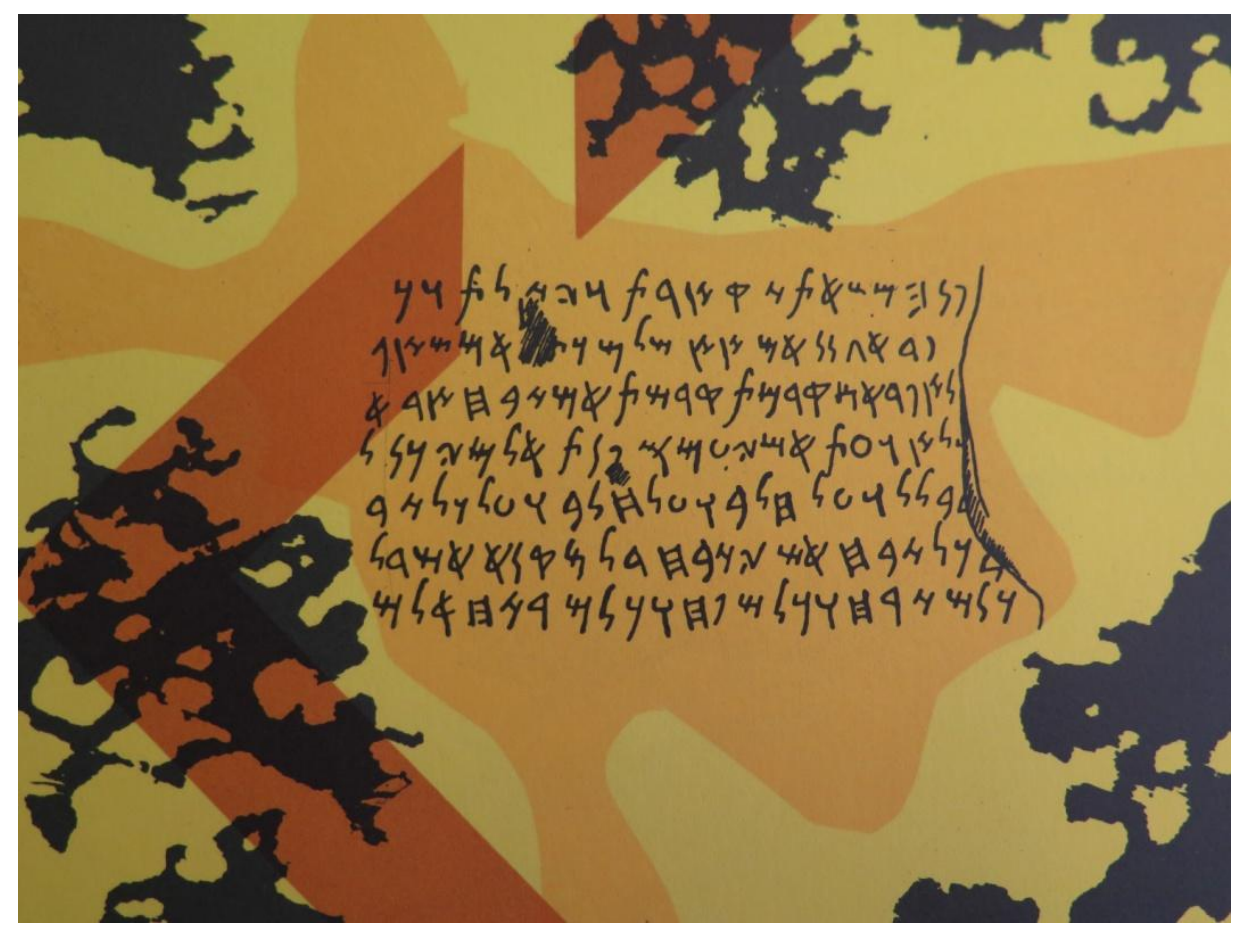

Figura 2 - DIAS PINO. Escritas arcaicas. 
Fonte: acervo da autora.

A prancha reproduzida na Figura 3, por exemplo, apresenta um fragmento que contém uma inscrição fenícia de Ahiram, possivelmente procedente de Biblos, do final do século XI a.C., que aparece também em uma prancha da Encyclopédie (Figura 4).

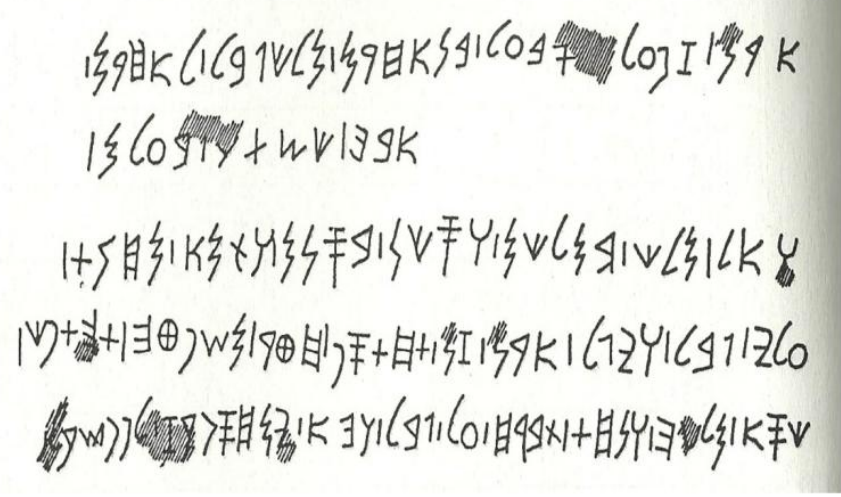

Figura 3 - Fragmento que contém uma inscrição fenícia de Ahiram, possivelmente procedente de Biblos, do final do século XI a.C.

Fonte: acervo da autora.

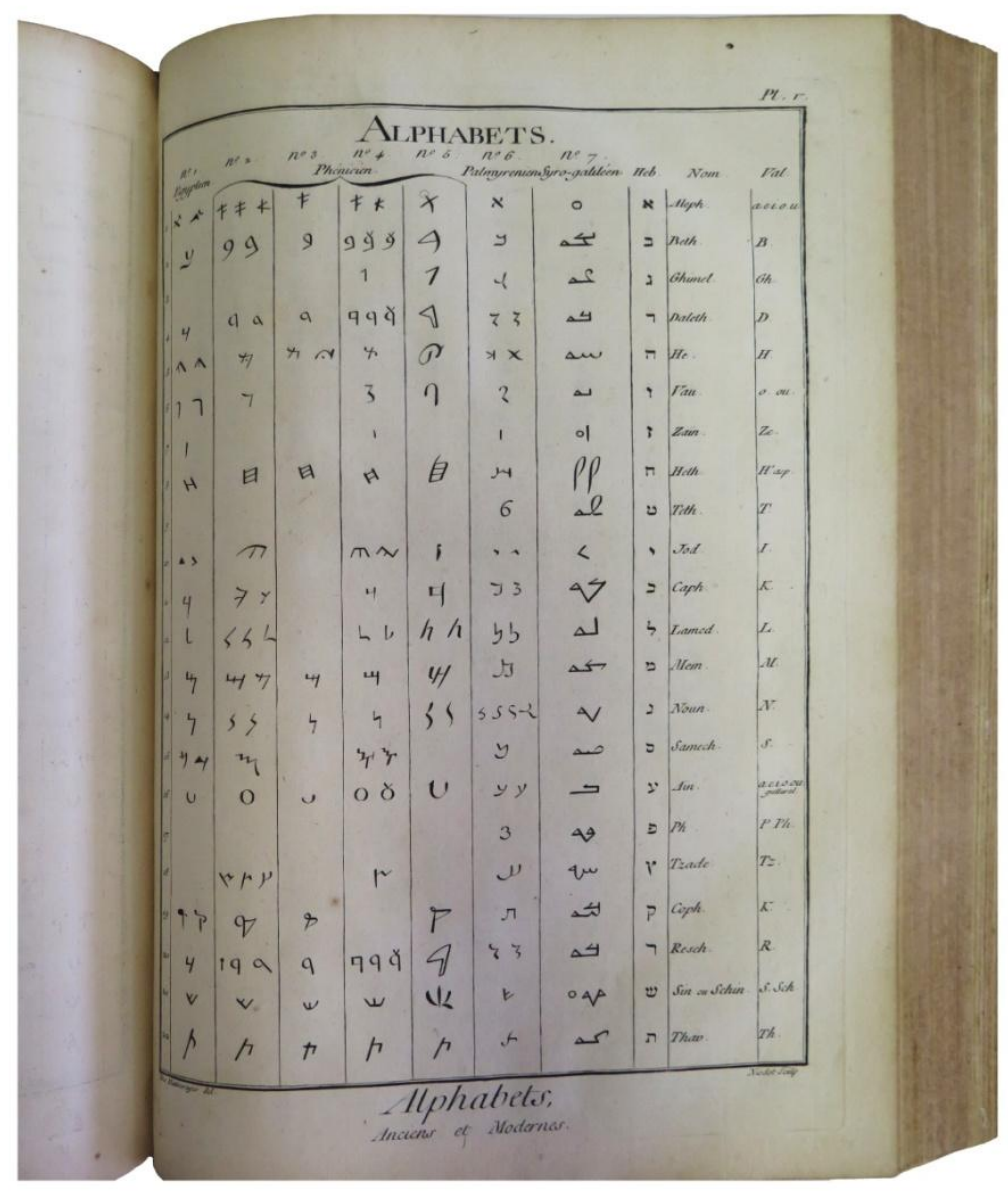


Figura 4 - Prancha da Encyclopédie, de Diderot e d'Alembert (alfabetos). Fonte: acervo da autora.

Outro exemplo da abordagem das escritas antigas por Dias-Pino surge na inscrição moabita (Figura 5) atribuída ao rei Mescha de Dibon (Jordânia), do século IX a.C., "citada" em uma das pranchas de Escritas arcaicas (Figura 6).

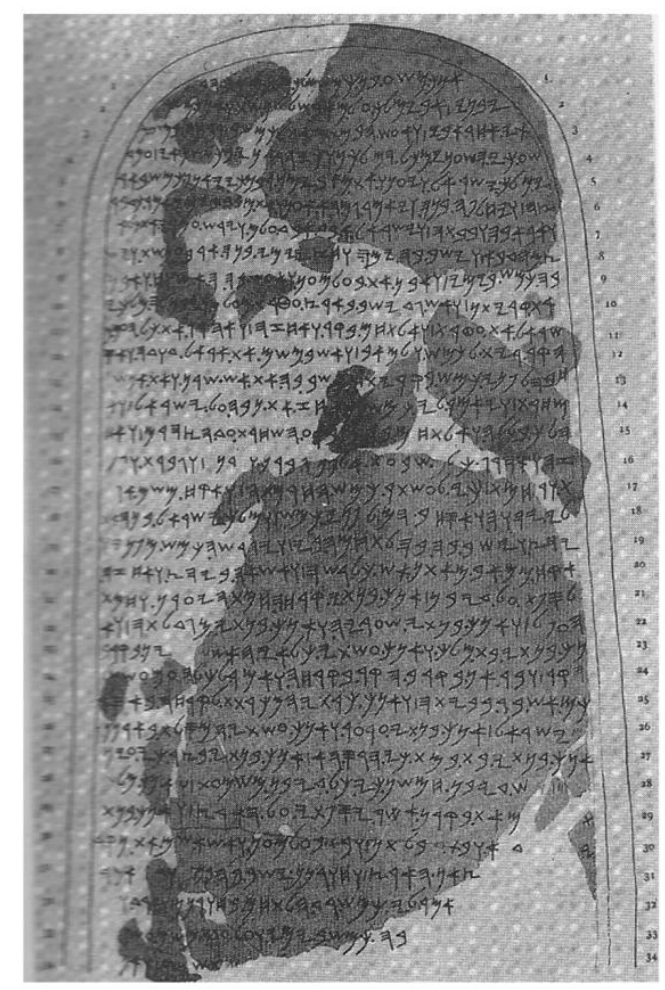

Figura 5 - Inscrição moabita atribuída ao rei Mescha de Dibon (Jordânia), do século IX a.C.

Fonte: acervo da autora. 


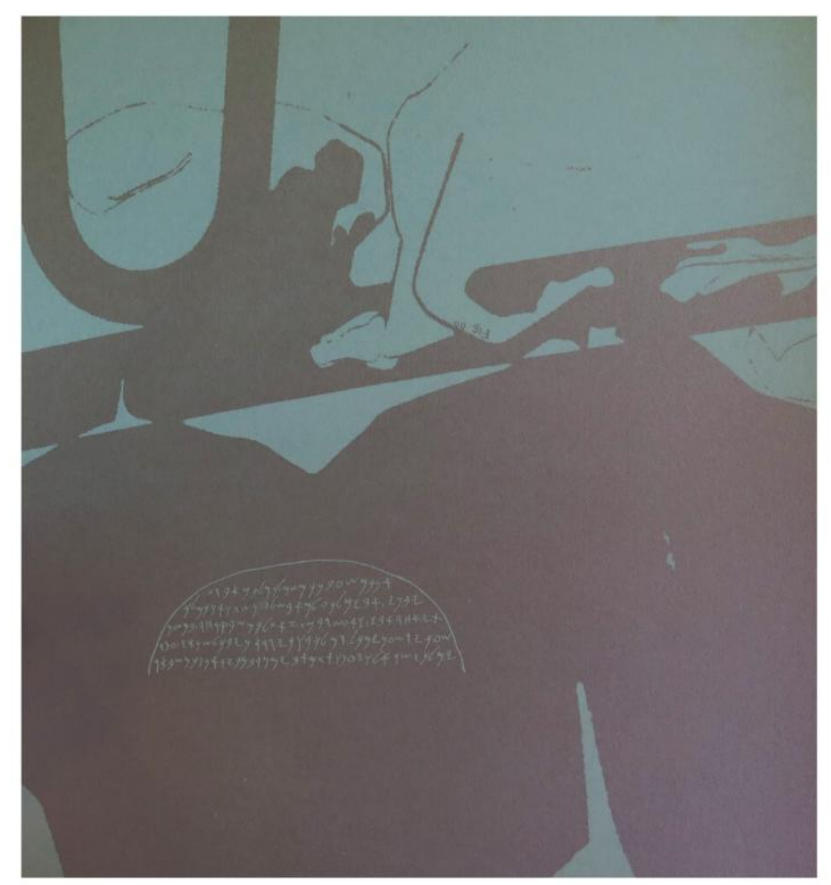

Figura 6 - DIAS PINO. Escritas arcaicas.

Fonte: acervo da autora.

Trata-se daquele que é considerado o melhor testemunho da forma mais antiga da escrita hebraica. A prancha seguinte (Figura 7) contém um fragmento que faz referência ao alfabeto tâmul ou malabar, também apresentado na Encyclopédie (Figura 8).

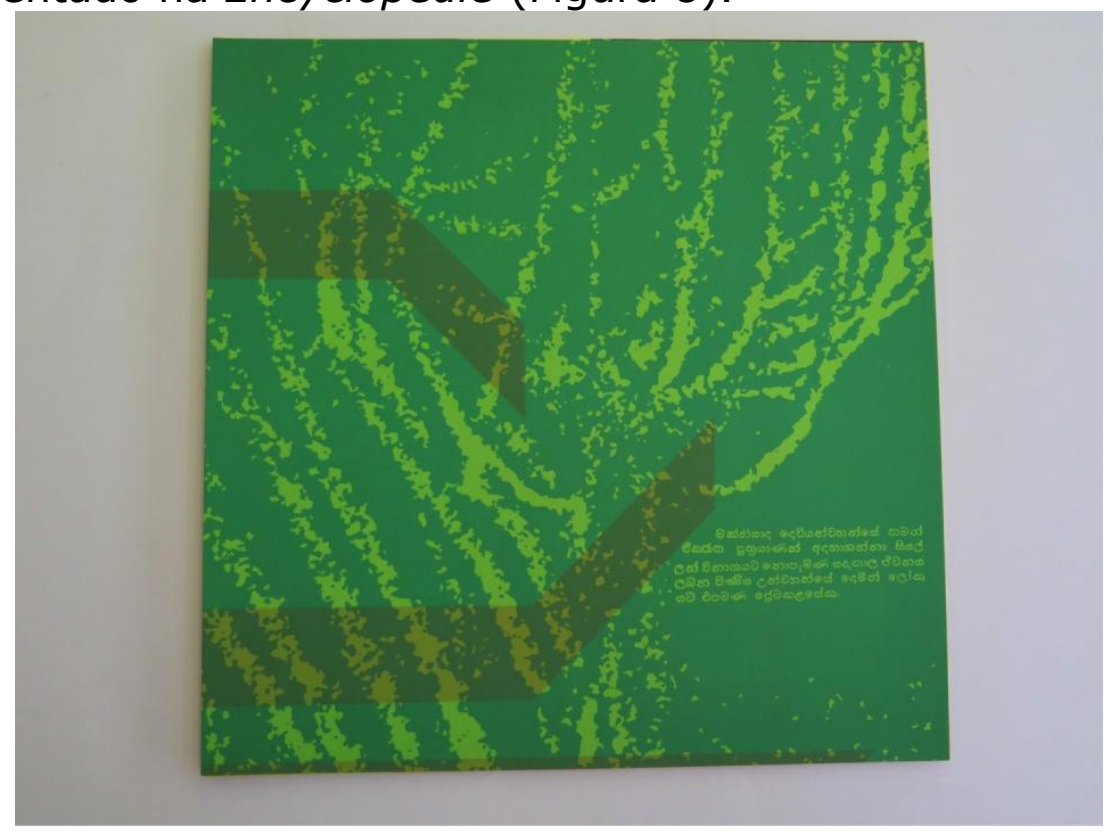

Figura 7 - DIAS PINO. Escritas arcaicas.

Fonte: acervo da autora. 


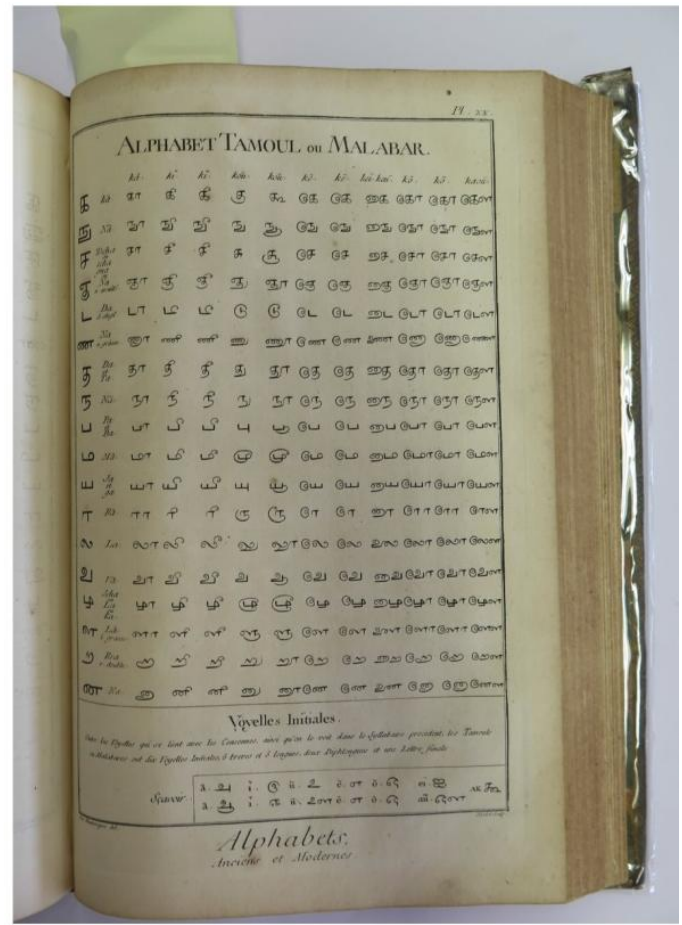

Figura 8 - Prancha da Encyclopédie, de Diderot e d'Alembert (alfabeto tâmul ou malabar).

Fonte: acervo da autora.

Ao aproximar a Enciclopédia visual e a Encyclopédie, nota-se que, enquanto a Encyclopédie pretende apresentar de maneira didática as escritas e os alfabetos conhecidos naquela época, cumprindo seu objetivo de conter todo o saber de meados do século XVIII, a Enciclopédia visual de Dias-Pino utiliza livremente fragmentos de palavras e alfabetos, considerando principalmente sua visualidade e criando conexões entre essas palavras e alfabetos e fundos que trazem texturas, formas orgânicas e formas geométricas, sobrepostas. Analisando essas combinações, percebe-se que o autor faz um contraponto ao desenho das letras apresentadas, que também são compostas por curvas e retas, as quais muitas vezes remetem a formas geométricas como o quadrado e o triângulo, chamando a atenção para a visualidade da escrita.

Enquanto a Enciclopédia visual é uma obra com características utópicas, que busca o conhecimento enciclopédico tendendo para um conhecimento universal, como já foi apontado, ao tentar abarcar a catalogação e a difusão do conhecimento sob a forma de imagens, a Encyclopedia, Contemporary Art in the World (2010), um projeto de JeanBenoît Lallemand, questiona a possibilidade de apreensão do conhecimento total ou universal. A capa dessa obra retoma a composição tipográfica da folha de rosto da Encyclopédie (século XVIII), porém limita sua ambição aos saberes que geram a ideia de "arte contemporânea", na época do Google.

Utilizando

- site

do

Google

Tradutor

(http://www.google.fr/language_tools), cada domínio local (França, 
Inglaterra, Alemanha etc.) foi objeto de uma pesquisa. O termo "arte contemporânea" foi traduzido para a língua oficial mais falada naquele país, por meio de pesquisas. Como alguns países, como o Irã, não têm domínio da internet - apesar de o Google permitir que seja efetuada uma tradução em farci (a língua persa) -, uma pesquisa foi então conduzida para as seis línguas afiliadas aos países que não possuem nenhum domínio. Na contracapa da Encyclopedia estão listadas as áreas que não oferecem a possibilidade de uma pesquisa específica, bem como áreas para as quais não há tradução possível com a ferramenta de tradução do Google. As primeiras nove imagens exibidas pela máquina de busca em cada país foram selecionadas para publicação (Figura 9).

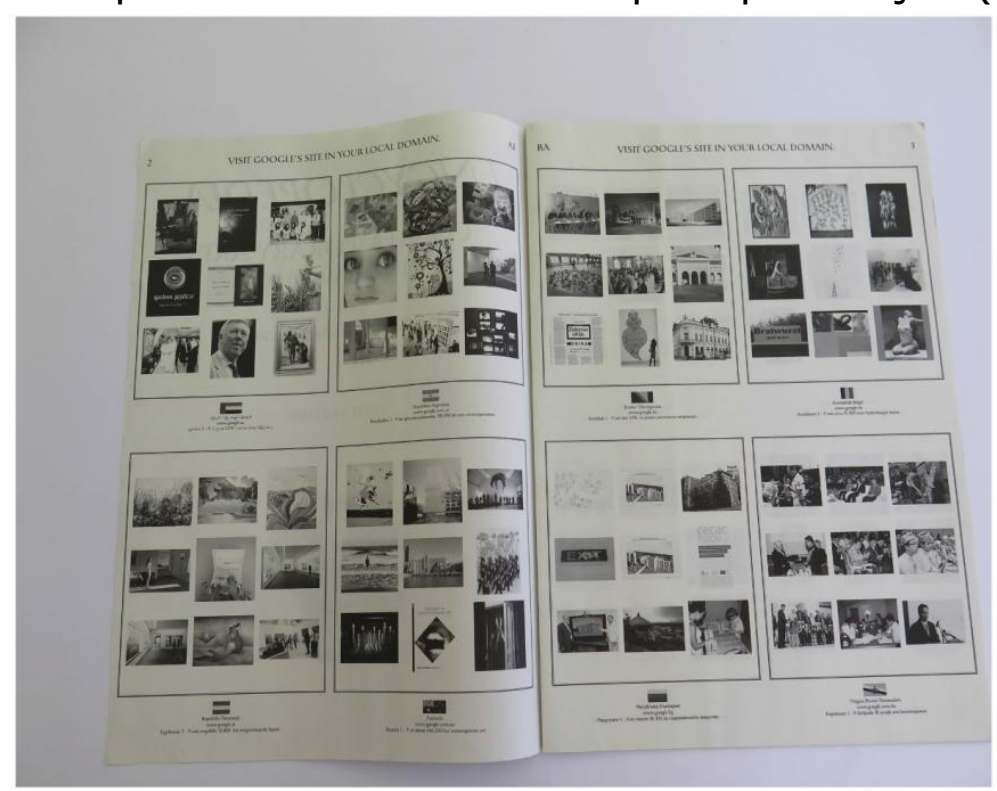

Figura 9 - LALLEMAND. Encyclopedia, Contemporary Art in the World.

Fonte: acervo da autora.

Escolhidas a partir da lógica de busca do Google, as imagens que aparecem relacionadas à "arte contemporânea" vão desde obras de arte que podem ser consideradas contemporâneas até registros aleatórios, que aparentemente em nada se relacionam ao tema, do ponto de vista do leitor ocidental, familiarizado com as buscas do Google.

A ideia da enciclopédia que fundamenta o projeto de Lallemand permite, pelo menos, vislumbrar os limites de um conhecimento do qual a internet é a ferramenta: as imagens são substituídas por conceitos, a ordem de apresentação das respostas do sistema Google depende do número de visitas a cada um deles, o resultado não é o mesmo de um dia para outro, etc.

\section{Considerações finais}

Ao aproximarmos as obras analisadas, nota-se que o enciclopedismo é um tema atual, que perpassa a arte e a cultura, algumas vezes reforçando os princípios do "conhecimento total" da Encyclopédie, e outras 
vezes contestando e subvertendo essa possibilidade de um saber universal, principalmente na época atual, na qual, apesar da facilidade de acesso à informação, muitas vezes ela não é absoluta, mudando de significado, dependendo do contexto em que é recebida, ou tornando-se simplesmente vazia de significado, um significante sem significado.

\section{Referências}

BLOM, Philipp. Enlightening the World: Encyclopédie, the Book that Changed the Course of History. New York: Palgrave Macmillan, 2005.

BURKE, Peter. Uma história social do conhecimento: de Gutenberg a Diderot. Rio de Janeiro: Zahar, 2003.

CADÔR, Amir Brito. O livro de artista e a enciclopédia visual. Belo Horizonte: Editora UFMG, 2016.

CHRISTIN, Anne-Marie (Ed.). A History of Writing: from Hierogliph to Multimedia. Paris: Flammarion, 2002.

CHRISTIN, Anne-Marie L'image écrite ou la déraison graphique. Paris: Flammarion, 2009.

DIAS-PINO, Wlademir. Escritas arcaicas. Rio de Janeiro: Europa, 1991. (Coleção Enciclopédia Visual, v. 447).

DIAS-PINO, Wlademir; SANTOS, João Felício dos. A marca e o logotipo brasileiros. Rio de Janeiro: Rio Velho, 1974. (Coleção Enciclopédia Visual, v. 1).

DIDEROT, Denis; D'ALEMBERT, Jean Le Rond. Encyclopedie, ou, Dictionnaire raisonné des sciences, des arts et des métiers: par une societé de gens de lettres. $3^{\mathrm{e}}$ éd. Genève: Jean-Léonard Pellet...; Neufchatel: Société Typographique, 1778-1779.

DRUCKER, Johanna. The century of artist's books. New York: Granary Books, 2004.

GARCIA, Angelo Mazzuchelli. A literatura como design gráfico. BH: C/Arte, 2013.

GARCIA, Angelo Mazzuchelli. O design gráfico do livro $A$ marca $e$ logótipo brasileiros. Revista Pós: Programa de Pós-Graduação em Artes da EBA/UFMG, Belo Horizonte, v. 2, n. 3, p. 120-136, maio 2012.

HOOKER, J. T. (Intr.). Lendo o passado: do cuneiforme ao alfabeto. A história da escrita antiga. São Paulo: EDUSP; Melhoramentos, 1996.

LALLEMANT, Jean-Benoît (Pesquisa e design). Encyclopedia, Contemporary Art in the World, with www.google.com/language_tools. Rennes: Éditions Incertain Sens; Centre Culturel Colombier, 2010. v. 1.

MALLARMÉ, Stéphane. O livro, instrumento espiritual. Trad. Tomás Maia. In: VALE, Paulo Pires do. Tarefas infinitas. Lisboa: Fundação Calouste Gulbenkian, 2012. Encarte. 
RODRIGUES, Márcia Carvalho. O que é livro raro?. 3 maio 2011. Disponível em: <http://www.dicyt.com/noticia/o-que-e-livro-raro>. Acesso em: 9 jun. 2017.

SALSANO, Alfredo. Enciclopédia. In: ENCICLOPÉDIA Einaudi. Lisboa: Imprensa Nacional; Casa da Moeda, 2000. v. 41: Conhecimento. p. 231.

SILVEIRA, Paulo. A página violada. Da ternura à injúria na construção do livro de artista. Porto Alegre: Editora da UFRGS, 2001.

VENEROSO, Maria do Carmo de Freitas. Caligrafias e escrituras: diálogo e intertexto no processo escritural nas artes no século XX. Belo Horizonte: c/Arte, 2012. 